STATEMENT OF INTEREST

None declared.

\section{REFERENCES}

1 Davies CW, Wimperis J, Green ES, et al. Early discharge of patients with pulmonary embolism: a two-phase observational study. Eur Respir J 2007; 30: 708-714.

2 Konstantinides S, Geibel A, Olschewski M, et al. Association between thrombolytic treatment and the prognosis of hemodynamically stable patients with major pulmonary embolism: results of multicenter registry. Circulation 1997; 96: 882-888.

3 Goldhaber SZ, Visana L, De Rosa M. Acute pulmonary embolism: clinical outcomes in the International Cooperative Pulmonary Embolism Registry (ICOPER). Lancet 1999; 353: 1386-1389.

4 Wicki J, Perrier A, Perneger TV, Bounameaux H, Junod AF. Predicting adverse outcome in patients with acute pulmonary embolism: a risk score. Thromb Haemost 2000; 84: 548-552.

5 Girard P, Sanchez O, Leroyer C, et al. Deep venous thrombosis in patients with acute pulmonary embolism: prevalence, risk factors, and clinical significance. Chest 2005; 128: 1593-1600.

6 Koopman MM, Prandoni P, Piovella F, et al. Treatment of venous thrombosis with intravenous unfractionated heparin administered in the hospital as compared with subcutaneous low-molecular-weight heparin administered at home. The Tasman Study Group. N Engl J Med 1996; 334 682-687.

7 Jiménez D, Yusen RD, Otero R, et al. Prognostic models for selecting patients with acute pulmonary embolism for initial outpatient therapy. Chest 2007; 132: 24-30.

8 Aujesky D, Obrosky DS, Stone RA, et al. Derivation and validation of a prognostic model for pulmonary embolism. Am J Respir Crit Care Med 2005; 172: 1041-1046.

DOI: $10.1183 / 09031936.00143907$

\section{From the authors:}

We would like to thank R. Otero and D. Jiménez for their comments and their support for the principle of outpatient management of pulmonary embolism (PE). However, we are surprised by the tone of their letter. We believe that patients should be considered for ambulatory care for the management of PE after appropriate risk stratification. This can take many forms, such as the criteria developed and used by my group, or use of validated prognostic scores, e.g. PE severity index scores. As stated in the original paper, this score gives a prediction of 30-day mortality rather than the more useful prediction of mortality within the acute low-molecular heparin treatment phase relevant to outpatient treatment of PE, and was also unpublished at the time the study was developed or performed [1]

Systolic arterial hypertension is a prognostic marker and relates to massive or submassive PE. As such, the patients in our study would fulfil other exclusion criteria given in points 1) and 2) of the Exclusion criteria for outpatient treatment section in the Methods of the original article [1].

The number of deaths reported in the data of R. Otero and D. Jiménez suggest that the population in this database who fulfilled our study criteria were somehow different to the actual patients we prospectively sent home for outpatient treatment. This highlights the fact that caution is needed when retrospectively trying to draw conclusions from applying exclusion criteria to a database cohort compared with a prospective cohort

Patient data suggests that patients prefer to be managed in an ambulatory fashion. Therefore, we believe that with appropriate risk stratification and patient information, we should offer this service to patients who fulfil the criteria quoted in our study [1]

\section{C.W.H. Davies}

Royal Berkshire NHS Foundation Trust, Reading, UK.

\section{STATEMENT OF INTEREST}

A statement of interest for C.W.H. Davies can be found at www.erj.ersjournals.com $/ \mathrm{misc} /$ statements.shtml

\section{REFERENCES}

1 Davies CWH, Wimperis J, Green ES, et al. Early discharge of patients with pulmonary embolism: a two-phase observational study. Eur Respir J 2007; 30: 708-714.

DOl: $10.1183 / 09031936.00156407$

\title{
Reference values for spirometry of the European Coal and Steel Community: time for change
}

To the Editors:

Recently, an American Thoracic Society (ATS)/European Respiratory Society (ERS) Task Force suggested the need for a new Europe-wide study to derive updated reference equations for lung function [1]. Until the results of such a study become available (we have been waiting for new reference values in Europe for $\sim 25 \mathrm{yrs}$ ), the official reference 
values in Europe are still those implemented by the European Coal and Steel Community (ECSC) [2] and the ERS [3]. The ATS/ERS Task Force has not commented on newer reference values for spirometry derived from the Swiss Study on Air Pollution and Lung Disease in Adults (SAPALDIA) [4, 5].

It has previously been pointed out that the main differences between the ECSC and the SAPALDIA reference values comprise the following two factors: 1) a shift to higher reference values; and 2) a nonlinear age dependency derived from newer studies [6]. It is highly plausible, and it has been corroborated by newer reference values, that there is a natural growth in values, followed by a steady change over and then a slow but growing decrease with age; the values are near optimal in $\sim 18$-yr-old females and $\sim 25$-yr-old males $[4,7]$.

It is of great importance, especially for longitudinal epidemiological studies, that age dependency at younger ages is highly different between the ECSC values (where it remains constant between ages 18 and $25 \mathrm{yrs}$, and is linear thereafter) and the newer reference systems (where it is nonlinear and shows a maximum). For example, the decrease in forced vital capacity (FVC) for a 180-cm tall male aged 21-50 yrs using the ECSC reference values is $22.4 \mathrm{~mL} \cdot \mathrm{yr}^{-1}$, but only $9.1 \mathrm{~mL} \cdot \mathrm{yr}^{-1}$ using reference values derived from SAPALDIA. Thus, decreases in FVC in longitudinal epidemiological studies will be detected with lower sensitivity if one uses the ECSC reference values.

The ECSC reference values for spirometry are not derived from measured data but, according to [2], from older reference equations that were obviously a combination of those from different researchers: "For each of the regression equations, a set of reference values was computed for each combination of height and age within the ranges given by the author [...] The summary equations as well as the residual standard deviations were calculated without weighting for numbers of subjects [...] In most publications, lung function is assumed to decline linearly with age in adults. However there is evidence that in young adults this is not the case (8 citations), and that the transition between the growth in adolescents and the decay with age in adults occurs at about 18-30 years of age [...]" [2]. We want to add that it is not known whether smoking was considered. Approximately 10 yrs ago, BAUR et al. [6] and RocA et al. [8] concluded that the present European recommendations on lung function reference values should be reconsidered, because "[...] the errors about the ECSC equations showed the most prominent underestimation of both predicted FVC [...] and predicted FEV1 [forced expiratory volume in one second]" [8].

Newer reference values derived from SALPALDIA are based on $\sim 3,000$ healthy nonsmoking 18-60-yr-old Europeans and meet the methodological, epidemiological and statistical criteria of the ATS for the selection of reference values $[9,10]$.

We suggest that the European Respiratory Society should withdraw immediately their official statement to use the European Coal and Steel Community reference values for spirometry as these are both incorrect and misleading. Furthermore, we question the need for a new study as an appropriate alternative is already available.

\section{P. Degens and R. Merget}

BGFA - Research Institute of Occupational Medicine, German Social Accident Insurance, Ruhr University, Bochum, Germany.

\section{STATEMENT OF INTEREST}

None declared.

\section{REFERENCES}

1 Pellegrino R, Viegi G, Brusasco V, et al. Interpretative strategies for lung function tests. Eur Respir J 2005; 26: 948-968.

2 Standardized lung function testing, Report Working Party. Bull Eur Physiopathol Respir 1983; 19: Suppl. 5, 1-95.

3 Quanjer PH, Tammeling GJ, Cotes JE, Pedersen OF, Peslin R, Yernault J-C. Lung volumes and forced ventilatory flows. Report Working Party Standardization of Lung Function Tests, European Community for Steel and Coal. Official Statement of the European Respiratory Society. Eur Respir J 1993; 6: Suppl. 16, 5-40.

4 Brändli O, Schindler C, Künzli N, Keller R, Perruchoud AP. Lung function in healthy never smoking adults: reference values and lower limits of normal of a Swiss population. Thorax 1996; 51: 277-283.

5 Brändli $\mathrm{O}$, Schindler $\mathrm{C}$, Leuenberger $\mathrm{PH}$, et al. Reestimated equations for 5th percentiles of lung function variables. Thorax 2000; 55: 173-174.

6 Baur X, Isringhausen-Bley S, Degens P. Comparison of lung-function reference values. Int Arch Occup Environ Health 1999; 72: 69-83.

7 Hankinson JL, Odencrantz JR, Fedan KB. Spirometric reference values from a sample of the general U.S. population. Am J Respir Crit Care Med 1999; 159: 179-187.

8 Roca J, Burgos F, Sunyer J, et al. Reference values for forced spirometry. Group of the European Community Respiratory Health Survey. Eur Respir J 1998; 11: 1354-1362.

9 Standardization of Spirometry, 1994 Update. American Thoracic Society. Am J Respir Crit Care Med 1995; 152: 1107-1136.

10 Lung function testing, selection of reference values and interpretative strategies. American Thoracic Society. Am Rev Respir Dis 1991; 144: 1202-1218.

DOI: $10.1183 / 09031936.00145507$

From the authors:

We thank P. Degens and R. Merget for giving us the opportunity to comment on the reference equations suggested by the American Thoracic Society/European Respiratory Society Task Force on lung function testing [1].

We agree with P. Degens and R. Merget when they say that the European Community for Coal and Steel reference equations for lung function are too old to be used in modern medicine due to their limitations in predicting lung function in the general population. Recognising this as an unresolved issue in the evaluation of lung function, the Task Force did not actually recommend "any specific set of equations for use in Europe"; instead, it suggested "the need for a new Europe-wide study to 